\title{
Educação ambiental crítica: do socioambientalismo às sociedades sustentáveis
}

\author{
Gustavo Ferreira da Costa Lima \\ Universidade Federal da Paraíba
}

\section{Resumo}

0 artigo reflete sobre o contexto histórico e teórico de formação da educação ambiental brasileira a partir da perspectiva do que se convencionou chamar de educação ambiental crítica. Partindo de um referencial teórico-conceitual da ecologia política, da teoria crítica e do pensamento complexo, problematiza as origens e os desdobramentos político-culturais, os argumentos e movimentos sociais que formataram essa tendência pedagógica de marcante presença na realidade educacional e ambiental brasileira. À luz desses referenciais, o artigo revisa e sistematiza a produção pertinente a esse novo campo de conhecimento e ação e, nesse sentido, dialoga, por meio desta produção, com os pesquisadores, educadores, agentes públicos e de organizações da sociedade civil que, nas décadas recentes, se envolveram com práticas e reflexões sobre a relação entre sociedade, educação e meio ambiente no Brasil. Investiga, para tanto, o debate, a diferenciação e as disputas internas ao campo da educação ambiental no Brasil, o processo de constituição do socioambientalismo que se coloca em contraposição a outra tendência conservacionista de educação ambiental e a construção de uma crítica a uma educação para o desenvolvimento sustentável, proposto pela UNESCO e demais setores interessados na conservação do status quo e numa sustentabilidade orientada pelas forças do mercado. Destaca, assim, em uma perspectiva histórica, as matrizes filosóficas, as posições político-pedagógicas e as forças sociais que inspiraram a emergência da educação ambiental crítica assim como as contribuições decisivas que esse processo legou ao avanço ético e político das relações entre a educação, a sociedade e o meio ambiente no Brasil.

\section{Palavras-chave}

Educação ambiental - Pensamento crítico - Ambientalismo - Desenvolvimento sustentável. 


\title{
Critical environmental education: from socio- environmentalism to sustainable societies
}

\author{
Gustavo Ferreira da Costa Lima \\ Universidade Federal da Paraíba
}

Contact:

Gustavo Ferreira da Costa Lima

Praça de Casa Forte, 534

52061-420 - Recife - PE

e-mail: gust3lima@uol.com.br

\begin{abstract}
The article is a reflection about the historical and theoretical contexts of the creation of environmental education in Brazil, from the perspective of what came to be called Critical Environmental Education. Starting from the theoretical and conceptual framework of political ecology, of critical theory, and of complexity thinking, the text problematizes the origins and the political-cultural unfolding, the arguments and social movements that have shaped this pedagogical trend of such marked presence in the Brazilian educational and environmental reality. The methodological path traversed here revisits and systematizes the literature pertaining to this new field of knowledge and action, and dialogues with our doctorate research which, for almost a decade, observed in loco the recent education initiatives in the field of environmental education in Brazil, following various events in this area, and interviewing significant sources of information belonging to social movements, public bodies and academic sectors associated with this field. In doing so, this article investigates the debate, the differentiation and the internal disputes in the field of environmental education in Brazil, the process of constitution of the socio-environmentalism that positions itself in opposition to a different conservationist trend in environmental education, and the construction of a critique to an education for the sustainable development - ESD, proposed by UNESCO and other sectors interested in the keeping of the status quo and in a sustainability oriented by market forces. It thereby highlights, under a historical perspective, the philosophical origins, the political-pedagogical positions, and the social forces that inspired the emergence of critical environmental education, as well as the decisive contributions that this process made to the ethic and political progress in the relations between education, society and environment in Brazil.
\end{abstract}

\section{Keywords}

Environmental education - Critical thinking - Environmentalism Sustainable development. 
A educação ambiental - EA - no Brasil se constituiu como um campo de conhecimento e de atividade pedagógica e política a partir das décadas de 70 e, sobretudo, de 80 do século próximo passado. Ela já nasceu como um campo plural e diferenciado que reunia contribuições de diversas disciplinas científicas, matrizes filosóficas, posições político-pedagógicas, atores e movimentos sociais.

A despeito dessa diversidade constitutiva, é possível perceber em seu núcleo orientador as tendências dominantes que forjaram seu perfil e que definiram o debate e a direção de sua trajetória histórica. A tendência crítica é uma dessas perspectivas político-pedagógicas centrais dentro do campo e é à sua compreensão que o presente artigo se dedica. Nesse sentido, propõe uma interpretação histórica e sociológica de suas origens sociais e políticas, de suas influências culturais, dos conflitos e das bases teórico-conceituais que permitiram formular essa perspectiva particular de abordagem da relação entre a educação, a sociedade e as questões ambientais.

A compreensão dos processos históricos, de diferenciação dos campos sociais e de seu desenvolvimento no interior da sociedade não só ilumina o passado, mas auxilia a compreensão e a ação presentes e a construção do futuro. Sempre quando aprofundamos a nossa consciência e discernimento sobre os processos sociohistóricos, ampliamos nossas possibilidades de escolha e nossa liberdade de ação frente à vasta e confusa oferta de informação que caracteriza o mundo contemporâneo. No caso da EA e do pensamento crítico, essa reflexão se valida tanto em relação à contribuição já acumulada quanto em relação aos novos desafios e debates criados e multiplicados continuamente pelo avanço da degradação ecossistêmica e das próprias relações sociais; pelo aprofundamento das desigualdades e exclusões sociais; pela enganosa difusão de discursos, como o desenvolvimento sustentável - DS - da educação para o desenvolvimento; e pela naturalização do mercado e das ideologias neoliberais como referências de regulação da policrise social.
A interpretação sugerida no presente artigo utiliza como referenciais de análise elementos teóricos e conceituais da ecologia política, da teoria crítica e de suas implicações na educação como é o caso da educação popular e do pensamento complexo. Particularmente, vamos explorar ao longo da trajetória da EA crítica um conjunto de noções principais como: cidadania ambiental, participação/democracia participativa, interdisciplinaridade, socioambientalismo e sociedade sustentável que, a meu ver, caracterizam e iluminam a trajetória dessa tendência de EA.

A ecologia política aparece como um quadro reflexivo e analítico - além de político - construído a partir dos anos 1970 por um conjunto diverso de contribuições que, em meu entender, explicita os motivos e argumentos expressos pela EA crítica, na medida em que promove a politização e a crítica dos problemas ambientais, de sua gênese, consequências, contradições e possíveis alternativas. Segundo Lipietz (2000):

A ecologia científica diz-nos quais são os efeitos de nossos comportamentos e práticas; esclarece-nos sobre o que está em jogo. Aos homens, no entanto, cabe-lhes escolher o modo de desenvolvimento que desejam, em função de valores que evoluem no curso de debates públicos. Levando a sério os desequilíbrios provocados pela atividade humana, a ecologia política vai interrogar-se sobre a modernidade e desenvolver uma análise crítica do funcionamento das sociedades industriais. Esta análise questiona um certo número de valores e de conceitos-chave sobre os quais se apóiam nossa cultura ocidental. (p. 2-3)

Nesse sentido, a ecologia política trouxe a contribuição das ciências humanas e sociais para a reflexão e o debate ecológico que, até então, eram pautados por leituras biologicistas e despolitizados dos problemas ambientais. Procura, justamente, incorporar aqueles elementos que os olhares disciplinares deixavam fora da aná- 
lise como: os modelos de desenvolvimento econômico-social, os interesses e conflitos de classe, os padrões culturais e ideológicos e as injunções políticas dominantes na sociedade.

Loureiro (2006), ao analisar as contribuições das teorias críticas à EA, ressalta que, em um sentido particular à teoria educacional, podem-se considerar como críticas todas as pedagogias divergentes da prática educativa tradicional marcada por

\section{[...] uma organização curricular fragmentada} e hierarquizada, neutralidade do conhecimento transmitido e produzido; e organização escolar e planejamento do processo de ensino e aprendizagem concebidos como pura racionalidade, pautados em finalidades pedagógicas desinteressadas quanto às implicações sociais de suas práticas. (p. 52)

Nesse sentido, seriam críticas não só teorias pedagógicas marxistas, mas também aquelas associadas à fenomenologia e à hermenêutica.

As influências criticas de origem marxista e/ ou frankfurtianas, que chamam nossa atenção nesse momento, chegam à educação ambiental brasileira por meio da educação popular, especialmente mediante a reflexão pedagógica e política de nomes como Paulo Freire, Carlos Rodrigues Brandão, Moacir Gadotti, entre outros. Gadotti e Torres (1994) definem a educação popular como uma alternativa político-pedagógica aos projetos educativos tradicionais dominantes, que se constituiu, simultaneamente, como modelo teórico e como prática social. Surgida das lutas em defesa dos interesses populares, a educação popular congregou e articulou diversas tradições político-ideológicas e pedagógicas, de alguma maneira convergentes, que incluem o marxismo e as pedagogias críticas, a teologia da libertação, a teoria da dependência, os movimentos sociais, as ONGs e os partidos políticos comprometidos com as lutas de resistência e emancipação das populações desfavorecidas e oprimidas como o camponês, o indígena, a mulher, o afro-americano, o analfabeto e o operário industrial. Tanto em teoria quanto em sua prática social, a educação popular se orientou e, segue se orientando, pela aspiração emancipadora dos educandos; pela prática educativa mais construtora que meramente difusora do conhecimento; pela defesa e produção de um ambiente educativo e social democrático e dialógico; pela articulação entre o processo educativo, a vida e as lutas sociais; pela recusa de toda forma de autoritarismo, domínio e manipulação humana, incluída as assimetrias entre professores e alunos; pela rejeição de uma ciência positivista, instrumental e reducionista; e pela transformação de todas as condições opressivas da vida humana, em especial daqueles já penalizados por sua condição social (Streck, 1996).

A perspectiva da complexidade se justifica pela premissa que compreende as questões ambientais como inerentemente interdisciplinares e multidimensionais, não sendo possível abordálas adequadamente por olhares disciplinares e reducionistas. Parte da constatação de que a modernidade avançada tem produzido e colocado, para a sociedade, uma qualidade nova de problemas decorrentes da própria reflexividade do conhecimento e/ou do avanço tecnológico que os saberes especializados e fragmentados não conseguem abarcar (Morin, 1996; Beck, 1997; Leff, 1999).

Vale ainda ressaltar que dialoga com minha pesquisa de doutorado ${ }^{1}$ que, por quase uma década, observou presencialmente a formação recente do campo da educação ambiental no Brasil, acompanhando inúmeros eventos da área e entrevistando informantes significativos dos movimentos sociais, de órgãos públicos e do setor acadêmico voltados ao tema.

Em resumo, o artigo que ora apresentamos pretende contextualizar, histórica e sociologicamente, a emergência do campo da educação ambiental no Brasil, observando em particular como nele teve surgimento uma tendência crí-

1. Lima, Gustavo Ferreira da Costa. Formação e dinâmica do campo da educação ambiental no Brasil: emergência, identidades, desafios. 2005. 207 p.Tese (Doutorado) - Instituto de Filosofia e Ciências Humanas, Universidade Estadual de Campinas, Campinas, SP, 2005. 
tica e explorando argumentos, motivos e objetivos que justificaram essa diferenciação dentro do campo e as contribuições educacionais e sociais daí decorrentes.

\section{O contexto histórico de surgimento da educação ambiental no Brasil}

Como vimos acima, a educação ambiental se constituiu no Brasil a partir das décadas de 1970 e 1980, como um campo complexo, plural e diverso, formado por um conjunto de atores e setores sociais que direta ou indiretamente exerceram influência em seus rumos como: os organismos internacionais, nomeadamente a ONU, a UNESCO e organismos financeiros associados; os sistemas governamentais de meio ambiente nas esferas federal, estadual e municipal; as associações, os movimentos e as ONGs ambientalistas representantes da sociedade civil organizada; as instituições científicas, educacionais ou religiosas; e as empresas de algum modo envolvidas com o financiamento ou desenvolvimento de ações educativas voltadas ao meio ambiente. Naturalmente essas influências não se exerceram de modo homogêneo nem com a mesma intensidade. No caso brasileiro, foram, sobretudo, decisivas no primeiro momento de sua constituição, as pressões dos organismos internacionais sobre o governo para instituir órgãos e políticas públicas ambientais, a ação da sociedade civil por meio dos movimentos sociais e das ONGs e as iniciativas pontuais e pioneiras de escolas e educadores inspirados por essa motivação renovadora.

De uma perspectiva cultural ampla, há que se considerar também múltiplas contribuições éticas, estéticas, político-ideológicas e teóricas provenientes dos movimentos de contracultura que marcaram a vida cultural do ocidente a partir dos anos 60 do século passado; das tradições anarquistas e socialistas; das teorias e pedagogias criticas veiculadas em grande medida pela educação popular; da produção e da cultura das ciências naturais; dos movimentos e debates preservacionistas e conservacionistas verificados na América do Norte; e das heranças do romantismo como movimento estético e sociocultural.

Essa seção, nesse sentido, trata de reconstituir as condições sociais e históricas, os fatos e os debates, os contextos e os movimentos, enfim, a atmosfera cultural e política que antecedeu, influenciou e abriu caminho para a formação do campo da EA no país.

Do ponto de vista político e institucional, o país vivia um período autoritário que se iniciara com o Golpe Militar de 1964 e só retornaria ao estado democrático de direito com a eleição indireta de um presidente civil em 1985, por meio da coalizão formada em torno da candidatura Tancredo Neves. Nesse clima de liberdades restritas, tanto a crítica e o debate político não prosperavam como a própria abordagem da questão ambiental sofria influências conservadoras. Isso porque a questão ambiental se desenvolvia e subordinava a uma orientação maior de governo de perfil desenvolvimentista, tecnocrático e autoritário, que demarcava claramente o sentido e os limites do que era possível avançar nessa área.

Uma das consequências do clima autoritário vigente à época sobre esse campo está na constatação de que a EA brasileira, em seus primórdios, foi orientada por uma visão hegemônica de perfil conservacionista, tecnicista, conservadora e apolítica, embora essa não fosse sua expressão exclusiva. Associado a isso, deve-se considerar a forte mediação do Estado brasileiro nesse processo de constituição do debate e da política ambiental brasileira em detrimento da sociedade civil e de uma cultura de participação social (Lima, 2005). Comentando esses reflexos sobre a EA então realizada, Loureiro (2004) esclarece:

Nesse contexto, a Educação Ambiental se inseriu nos setores governamentais e científicos vinculados à conservação dos bens naturais, com forte sentido comportamentalista, tecnicista e voltada para o ensino de ecologia e para a resolução de problemas. Evidentemente 
que já havia perspectivas críticas que vinculavam o social ao ambiental, mesmo entre setores de órgãos de meio ambiente como a FEEMA (Fundação Estadual de Engenharia e Meio Ambiente), no Rio de Janeiro, e a CETESB (Companhia de Tecnologia de Saneamento Ambiental), em São Paulo, que realizaram importantes cursos e produziram alguns textos e guias didáticos excelentes nos anos setenta e oitenta, contudo não eram tendências hegemônicas (como não são) nem possuíam, à época, grande capilaridade no tecido social. (p. 80)

Outro registro importante nesse processo é o fato de que a EA brasileira se constituiu principalmente a partir de iniciativas dos órgãos de meio ambiente em detrimento dos órgãos educacionais propriamente ditos como seria de se esperar. Segundo Dias (1991):

\section{[...] enquanto o sistema educacional brasilei-} ro não assimilava as novas idéias os órgãos ligados ao meio ambiente resolveram tomar a questão para si, o que não foi ruim, pois, do contrário, ainda estaríamos na estaca zero. (p. 6)

Como veremos adiante, essas concepções e tendências incorporadas pela EA brasileira estão entre os motivos contra os quais se levantará mais tarde a tendência crítica.

Lima (2005) também problematiza essa influência do ciclo autoritário e tecnocrático sobre a educação ambiental hegemônica no período, considerando que:

[...] a interpretação e o discurso conservacionista que conquistou a hegemonia do campo da EA no Brasil em seu período inicial foi vitoriosa entre outras razões, porque se tornou funcional às instituições políticas e econômicas dominantes, conseguindo abordar a questão ambiental por uma perspectiva natural e técnica que não colocava em questão a ordem estabelecida. Inspira- do por uma perspectiva de pretensa neutralidade ideológica, que não problematizava os aspectos políticos, econômicos e éticos da questão ambiental e não exigia mudanças profundas na vida social, o conservacionismo pôde ser assimilado pacificamente, sem grandes traumas. (p. 112)

Outra consequência relevante do período autoritário sobre a EA, em particular, e sobre o ambientalismo, em geral, foi a migração de quadros políticos de esquerda para a militância ambiental, justamente porque os movimentos ecológicos não eram identificados pelo governo autoritário à época como movimentos políticos. Isso permitia a esses setores um tipo de atuação que lhes era vedada pela suspensão das liberdades democráticas e que canalizava as energias políticas bloqueadas mediante essa nova militância. Esse deslocamento e interesse de setores de esquerda pelo debate e pela militância ambiental agregou ao pensamento ambiental e ao ambientalismo, como movimento, um elemento crítico e social, proveniente das tradições anarquistas e socialistas, que foram decisivos na orientação dos campos ambiental e da EA.

Deve-se ainda dizer que o fechamento do ciclo autoritário, na segunda metade dos anos 1980 e o início do processo de redemocratização, deu margem à emergência de uma ampla variedade de movimentos sociais, associações e ONGs, inclusive voltadas à questão ambiental, que deram força às lutas sociais e aos debates ambientais e criaram um ambiente propício para o diálogo e a aproximação entre esses dois setores. Voltaremos a esse ponto quando analisarmos a emergência do socioambientalismo no contexto de desenvolvimento da EA na segunda metade dos anos 1980 .

Como já indicamos acima, o desenvolvimentismo, como ideologia político-cultural dominante no período, é outro elemento desse contexto que orientou os debates, os discursos e as políticas ambientais. A influência de ideias desenvolvimentistas entre nossas elites dirigentes, e sobre a orientação da política eco- 
nômica no período do pós-guerra, é outro fator que incidiu sobre a maneira com que a questão ambiental foi tratada no contexto brasileiro. Para o pensamento desenvolvimentista, o discurso ambiental representava um obstáculo ao crescimento econômico - e ao industrialismo tido à época como a resposta a todos os problemas sociais do país. Considere-se que, do ponto de vista econômico, o Brasil vivia a fase de crescimento industrial acelerado, que ficou conhecida como o Milagre Brasileiro - sobretudo no período 1969-1973 - e, nesse contexto, a defesa da preservação ambiental aparecia para o governo e seus ideólogos como uma interferência indesejada. Basta dizer que na Conferência Internacional da ONU sobre Meio Ambiente realizada em Estocolmo em 1972, a delegação do governo brasileiro liderou a resistência dos paises periféricos em defesa do crescimento industrial "a qualquer custo" e contra o que entendiam como manobras dos países centrais para impedir o seu crescimento. Essa iniciativa chegou a ponto de veicular nos meios de comunicação europeus o convite às empresas que desejassem instalar plantas industriais poluentes no Brasil e que tivessem sofrendo restrições das legislações de seus países.

A ideologia desenvolvimentista também permeava o ideário de setores da esquerda brasileira e foi responsável, durante um largo período, por uma compreensão equivocada que via a questão ambiental como dissociada e antagônica à questão social. Para esses setores, a pobreza e a questão social eram nossas prioridades e o problema da degradação ambiental era um luxo reservado aos países desenvolvidos - uma ideologia importada - que desviava nossa atenção dos 'verdadeiros' problemas do país. Essa compreensão, que atravessou e ainda cruza o debate ambiental no Brasil, dificultou a formação de alianças significativas entre as entidades ambientalistas e os demais movimentos sociais - sindicatos e centrais de trabalhadores urbanos e rurais, seringueiros, indígenas e mulheres - que só veio a se estabelecer a partir da segunda metade da década de 1980, formando o que ficou conhecido como o socioambientalismo. Contribuiu também, para essa dissociação entre o social e o ambiental, a excessiva ênfase da militância ambientalista inicial em torno de valores e demandas estritamente ecológicas e a falta de habilidade política em descobrir a convergência entre as agendas ambiental e social (Ferreira, 1999; Viola, 1992).

Pode-se dizer que o amadurecimento da experiência e do debate ambiental e político fez revelar, a ambientalistas e membros dos movimentos sociais, que as questões social e ambiental não eram antagônicas, mas complementares, e que a degradação que atingia a sociedade e o ambiente eram produzidas por um mesmo modelo de desenvolvimento que, em última instância, penalizava, preferencialmente, a qualidade de vida dos mais pobres.

Com a difusão da proposta de DS, a partir de 1987, quando foi publicado o Relatório Brundtland, foi possível renovar o debate sobre o desenvolvimento e reorientar as concepções maniqueístas que contrapunham desenvolvimento e meio ambiente em busca de modelos capazes de conciliar a atividade econômica e a proteção ambiental.

Como comenta Guimarães (1995), ficava cada vez mais claro que a dimensão da crise não se reduzia, como à época da Conferência de Estocolmo, a uma questão de como manter limpos os ecossistemas e os recursos dos quais dependem nossa sobrevivência. Uma nova consciência constatava a impossibilidade de contrapor os problemas do meio ambiente e do desenvolvimento simplesmente porque esses problemas eram resultantes do próprio modelo de desenvolvimento posto em prática.

Do ponto de vista internacional, as grandes conferências e os encontros das Nações Unidas a partir dos 1970 e os debates internacionais desencadeados a partir do Relatório Meadows não só promoveram a publicização da questão ambiental como forneceram uma base argumentativa que alimentava a nascente consciência ambiental. Embora tivesse aspectos problemáticos, o Relatório Meadows desconstruía o 
mito econômico que apostava num crescimento econômico infinito a partir de uma base de recursos naturais, cada vez mais, percebida como finita e vulnerável à expansão capitalista.

Nessa busca de respostas teóricas e práticas de enfrentamento da crise ambiental, sempre se colocou a questão de como utilizar a educação como instrumento para criar e promover valores, ideias, sensibilidades e atitudes favoráveis à preservação do meio ambiente. Por meio da educação, tratava-se, então, de estimular uma socialização pró-ambiente, capaz de explorar suas funções de reprodução cultural naquilo que a herança cultural valoriza: a vida humana, social e natural, e de transformação cultural daqueles aspectos da tradição e a da cultura dominantes que produzem processos de degradação da vida social e ambiental.

Importa, contudo, considerar que a educação é um subsistema subordinado e articulado ao macrossistema social, apesar de dotado de particularidades e autonomia relativa. Nesse sentido, as concepções e práticas educacionais se inscrevem e relativamente se subordinam a um contexto histórico mais amplo que condiciona seu caráter e sua direção pedagógica, política e cultural. Isso quer dizer que os debates internos ao campo da educação, como da EA, acompanham e são tributários dos macrodebates sociais, apresentando o mesmo espectro de valores, interesses e ideologias que caracterizam sua diversidade. São esses macrodebates político-ideológicos em torno de modelos concorrentes de sociedade e desenvolvimento que terminam orientando as políticas nos planos educacional, tecnológico, científico, produtivo, trabalhista, entre outros. Nesse sentido, o debate sobre a EA guarda uma correspondência direta com as clivagens que disputam o campo do ambientalismo e da sustentabilidade de um modo geral, assumindo variações em torno de um eixo polarizado pelo conservadorismo e pela emancipação.

Ou seja, o processo educativo não é um processo neutro e objetivo, destituído de valores, interesses e ideologias. Ao contrário, é uma cons- trução social repleta de subjetividade, de escolhas valorativas e de vontades políticas dotado de uma especial relevância social por sua capacidade de reproduzir ou transformar a ordem social. Assume, portanto, uma função estratégica por estar diretamente envolvida na socialização e formação dos indivíduos e de sua identidade social e cultural. A educação, nesse sentido, pode assumir tanto um papel de conservação da ordem social, reproduzindo os valores, as ideologias e os interesses dominantes socialmente, como um papel emancipatório, comprometido com a renovação cultural, política e ética da sociedade e com o pleno desenvolvimento das potencialidades dos indivíduos que a compõem.

No caso ora observado, o que queremos destacar é que a EA brasileira, como campo social, assumiu no período inicial de sua constituição as características do contexto político, sociocultural e pedagógico hegemônicos naquele momento. No caso brasileiro, vimos como essas características tendiam para um perfil conservacionista, tecnicista, conservador e apolítico. Isso não significa dizer que essa tendência conservacionista era única e universal, mas que, compreendida em um campo discursivo múltiplo e em disputa com as outras concepções existentes, revelava-se como a expressão dominante no período.

$\mathrm{Na}$ seção seguinte, vamos explicitar o significado desse perfil e os motivos que fizeram com que uma perspectiva crítica de EA se insurgisse contra ela.

\section{A educação ambiental conservacionista, a resistência crítica e o socioambientalismo}

0 que se convencionou chamar de educação conservacionista no contexto de constituição da EA brasileira faz referência a um conjunto de características epistemológicas, pedagógicas, políticas e éticas, expressas nos discursos e nas práticas educativas realizadas pelos atores envolvidos nesse campo social e que foram objeto de crítica por parte dos educadores e pesquisadores envolvidos nesse debate. 
Procurarei, a seguir, problematizar essas características enquanto apresento o diálogo, as divergências e os argumentos formulados por aqueles que defendiam uma EA crítica em oposição à corrente conservacionista, então hegemônica. Para pensarmos dinamicamente a disputa discursiva e de hegemonia dentro do campo da EA brasileira, é útil distinguirmos o que poderíamos denominar o núcleo orientador do campo composto pelos professores/educadores, pesquisadores e técnicos que ocuparam posições de orientação teórica, política e ideológica do campo e sua periferia formada pelos professores dos vastos rincões do país que se ocupavam da tarefa de implementar as diretrizes definidas pelo núcleo orientador.

A EA conservacionista sofreu uma forte influência do ethos das ciências naturais, como de resto o próprio ambientalismo, no sentido de que se utilizou das teorias, dos conceitos e de uma visão de mundo biologizante que brotava desse universo particular. Segundo Lima (2005), esse fato decorre, entre outras razões, do pioneirismo dos cientistas naturais em perceber e denunciar as mudanças e os impactos ambientais que observavam em suas pesquisas de campo, o que lhes atribui méritos inegáveis reconhecidos consensualmente. Outra questão inevitável, e dessa vez decorrente da fragmentação e especialização do conhecimento, é que biólogos e cientistas naturais tendem a ter olhos e hábitos relacionados à sua área de formação e a enfatizar as dimensões da realidade que lhes são concernentes. Quero dizer que tenderam a destacar os aspectos naturais ou ecológicos dos problemas ambientais em detrimento de seus aspectos sociais, políticos, econômicos e culturais. Não quero com essa afirmação ser determinista ou reduzir o universo dos cientistas naturais, mas apenas constatar um déficit de elementos sociais em certos setores e fases - sobretudo as iniciais - dos debates ambientais e da EA em particular.

Como isso se manifestava e que implicações produzia? Se manifestava pela tendência a expressar uma compreensão ecológica da crise ambiental e a não explorar os aspectos político-sociais desse processo como: a natureza dos modelos de desenvolvimento econômico; os conflitos e interesses de classe que dão seus contornos; a abordagem ideológica da questão ambiental, que pode ser mais neutra ou mais política; a dissociação da degradação ambiental e social e dessa dupla degradação com a ordem capitalista; a ausência de uma crítica da ciência e do Estado como instituições não neutras nesse processo; a indiferenciação das responsabilidades sociais dos agentes causadores dos problemas ambientais; a escassa problematização da relação entre economia e ecologia e, dentro disso, da desmistificação da economia como esfera autônoma e autossuficiente; entre outros problemas.

Assistimos e continuamos a observar, nos debates e discursos ambientais, afirmações genéricas e abstratas que apontam "o homem como o grande adversário da natureza” ou que mencionam as "ações antrópicas" como responsáveis pela crise ambiental. Em sentido genérico e coloquial, não estão incorretas, mas carecem de precisão, aprofundamento e crítica e acabam contribuindo para formar uma representação simplista do problema.

Essa dissociação entre os aspectos biológicos/ecológicos e os aspectos políticos e sociais da crise ambiental é um dos argumentos centrais da EA crítica que, partindo de outro diagnóstico, destacava o caráter estrutural e civilizatório da crise ambiental e a necessidade de respostas transformadoras tanto políticas quanto éticas da questão. Segundo sua compreensão, os impactos ecológicos eram apenas os efeitos de causas muito mais profundas que indicavam a degeneração de todo um modelo civilizatório baseado em opções políticas e valorativas predatórias e nocivas à vida social e natural. Nesse sentido, não aceitavam respostas paliativas e monodimensionais que desprezavam a centralidade política da questão ambiental, as contradições e os conflitos nela revelados e a oportunidade de questionar e de transformar em profundidade o modelo social vigente. Essa politização dos problemas ambientais e de seu encaminhamento inova também ao abor- 
dar o direito à vida e a um ambiente saudável como uma questão de cidadania, ampliando essa noção para além dos limites estritos do contrato social liberal.

Esse tipo de compreensão conservacionista, justamente por privilegiar os efeitos às causas dos problemas ambientais, tendia igualmente a assumir posições tecnicistas que, diante da evidência dos impactos ambientais, prescreviam soluções tecnológicas para problemas que, na verdade, exigiam respostas de maior complexidade.

Essa tendência tecnicista se associa e revela outro problema recorrente no debate e na abordagem das questões ambientais: o otimismo tecnológico. Essa sobrevaloração da tecnologia acompanha toda a trajetória do ambientalismo e configura-se como o grande argumento daqueles setores contrários, por motivos diversos, aos alertas e às denúncias dos setores mais críticos. Em síntese, expressa a ideia de que a questão ambiental tem sido superestimada, que não há motivos reais para tanto alarde e que o desenvolvimento tecnológico será sempre capaz de nos socorrer das ameaças e dos riscos ambientais. 0 próprio debate recente sobre as mudanças climáticas foi e continua sendo mesmo após a divulgação dos relatórios do IPCC - atravessado por argumentos desse tipo, que tendem a minimizar a dimensão dos problemas e a maximizar o alcance e a capacidade das soluções tecnológicas. A título de esclarecimento, diga-se que os últimos relatórios do Painel Internacional sobre Mudanças Climáticas - IPCC das Nações Unidas: conselho científico da ONU instituído com o objetivo de estudar o fenômeno do aquecimento global e das mudanças climáticas e formular recomendações às Nações Unidas e aos seus países membros - concluíram, após décadas de pesquisas e debates científicos e políticos, que o aquecimento global tem de 90 a 99\% de probabilidade de ser produto da ação humana e não de causas naturais cíclicas como advogavam outros intérpretes.

Nesse sentido, o tecnicismo, seja o de caráter ingênuo seja o político-ideológico, tem consequências nocivas porque reduz a complexi- dade dos problemas ambientais à sua dimensão técnica; porque parte da premissa oculta de que a técnica é neutra e não política; porque tende a protelar a tomada de iniciativas para combater o avanço da degradação ambiental; e porque desconsidera o princípio ético da precaução que defende a prevenção sempre quando o debate científico indicar incerteza e dúvida.

0 tecnicismo também recebe críticas de mais duas direções. Em primeiro lugar, ao partir da consideração da ciência como único saber válido, a ênfase técnica tende a excluir todos os demais saberes populares, tradicionais, religiosos, artísticos e filosóficos construídos pela acumulação histórica com amplo potencial de contribuição aos problemas ambientais contemporâneos. A outra fonte de crítica contrapõe as respostas técnicas às respostas éticas argumentando que a esfera técnica é a dimensão dos meios enquanto a esfera ética corresponde à dimensão dos fins sociais. Ora, restringir a questão ambiental à discussão dos meios é uma estratégia instrumental que reduz nossa condição humana ao fazer, implementar e negar nosso direito de discutir os fins e os objetivos éticos e sociais, ou seja, por que e para que agimos e em que direção para corresponder exatamente ao tipo de vida e sociedade que julgamos desejável.

Como já indicamos, o tecnicismo inerente ao conservacionismo é herdeiro direto do paradigma cientificista e dualista moderno que lançou as bases epistemológicas de todo o pensamento ocidental. Esse pensamento marcado pelo humanismo, pelo mecanicismo e pelo racionalismo instaurou a fragmentação e a separação entre homem/cultura e natureza, entre sujeito cognoscente e objeto conhecido, entre razão, sensibilidade e emoção que posteriormente se multiplicou em outras tantas dicotomias como desenvolvimento e meio ambiente, consumo e produção, ciências naturais e sociais, técnica e ética, entre outras.

Para Grun (1996):

É na base dessa cisão radical entre sujeito e objeto que se pautará praticamente todo o 
conhecimento científico subsequente. 0 sujeito é o cogito (a razão) e o mundo, seu objeto. É na base desse dualismo que encontramos a gênese filosófica da crise ecológica moderna, pois a partir dessa cisão a natureza não é mais que um objeto passivo à espera do corte analítico. Os seres humanos retiram-se da natureza. Eles olham a natureza como quem olha uma fotografia. A natureza e a cultura passam a ser duas coisas muito distintas. Aliás, este é o novo ideal da educação: distinguir-se o mais possível da natureza, tornar-se humano. (p. 35)

Essa crítica à razão moderna é um elemento de destaque da EA crítica que tende a rejeitar o antropocentrismo e consequente subordinação da natureza; a fragmentação e a perda da interdependência inerente à existência; o reducionismo e o objetivismo que acabam sacrificando tanto os aspectos não racionais da realidade quanto toda a subjetividade humana; a pretensão positivista de uma neutralidade ideológica e inalcançável; e o utilitarismo de uma razão que instrumentaliza a exploração e dominação dos seres humanos e da natureza. Criticase, nesse sentido, o paradigma moderno pelo seu poder de imprimir as características acima às relações sociais, às relações da sociedade com a natureza e consequentemente às relações no plano educacional. Nesse sentido, revela a crise do paradigma moderno na medida em que ele não responde aos problemas de alta complexidade da vida contemporânea como é o caso dos problemas ambientais.

Do ponto de vista pedagógico, a EA conservacionista se expressa de maneira individualista e comportamentalista por compreender que a gênese dos problemas ambientais está mais relacionada à esfera individual, moral e privada do que à esfera coletiva, pública e política e, nesse sentido, voluntária ou involuntariamente, se associa a uma interpretação liberal ou mesmo neoliberal da crise ambiental. Seu diagnóstico da destruição ambiental, com ênfase nos indivíduos, conclui que estes agem dessa maneira porque desconhecem a dinâmica ecossistêmica e sua relação com a vida humana. Seriam, segundo esse raciocínio, desinformados e insensíveis a essa dinâmica das relações entre a sociedade e a natureza. A partir dessa visão, a tarefa educativa seria a de transmitir os conhecimentos corretos, de informar e sensibilizar as pessoas, apelando para o seu bom senso moral, o que em poucas palavras pode ser sintetizado como a mudança dos comportamentos humanos em sua relação com o ambiente.

Orlandi (1996), ao analisar o discurso da EA veiculado por essa produção inicial do campo, observa seu teor comportamentalista e normativo que também poderíamos classificar como educação/adestramento em contraposição a uma educação com sentido de autonomia:

Chegamos, enfim à crítica mais consequente ao material que analisamos e que se configura como discurso de educação ambiental: é um discurso que se inscreve no "comportamentalismo" com todos os inconvenientes que vejo nessa posição e em seus efeitos. Dentre esses, destaca-se seu efeito moralista, doutrinário e autoritário (sob o modo paternalista ou iluminista). (p. 47)

Carvalho (1995), sem negar as dimensões individuais e comportamentais das questões ambientais, também problematiza 0 comportamentalismo da EA, destacando a parcialidade de se restringir a questão ambiental ao campo da esfera privada, dissociando-a do campo da ação política e da cidadania. Sobre isso, considera que:

[...] é preciso recolocar os objetivos da prática educativa, situando-os para além da esfera comportamental. Se a educação quer realmente transformar a realidade não basta intervir na mudança dos comportamentos sem intervir nas condições do mundo em que as pessoas habitam... Neste sentido, podemos redefinir a prática educativa como 
aquela que, juntamente com outras práticas sociais, está implicada no fazer histórico, é produtora de saberes e valores e, por excelência, constitutiva da esfera pública e da política, onde se exerce a Ação humana. (p. 33)

0 comportamentalismo é assim criticado tanto porque reduz a complexidade do agir humano à dimensão comportamental quanto porque reduz à esfera individual e privada questões públicas e políticas inexoravelmente dependentes de mediações socioculturais (Carvalho, 2002b).

Outras considerações pedagógicas são apresentadas contra a educação conservacionista que decorrem, em última instância, de suas premissas epistemológicas positivistas. Há, por exemplo, a crítica a uma visão de educação como difusão de conhecimentos que se alicerça numa relação assimétrica, opressora e apassivadora entre o educador e o educando, bem explorados pelas pedagogias críticas entre as quais se destaca a pedagogia freireana, de forte presença no seio da EA crítica. Inspirada nesses propósitos, faz-se a defesa de uma pedagogia que entende educação e conhecimento como uma construção social dialógica e coletiva, que persegue o pensamento crítico, a formação de sujeitos emancipados e a transformação da realidade sociocultural e política.

Dentro dessa mesma concepção educativa, por natureza democrática, participativa e inclusiva, cabe explorar não apenas o diálogo interno ao ambiente pedagógico como também sua relação com a vida comunitária, na qual a prática educativa ocorre, especialmente quando a dimensão ambiental - na verdade socioambiental - é o foco privilegiado.

Com relação ao diálogo intraescolar, a EA crítica alimenta o desejo de uma renovação profunda de todo ambiente educativo a partir de seu sistema de ensino-aprendizagem, seus métodos, princípios epistemológicos e paradigmáticos, conteúdos curriculares, formas de organização e relação com o entorno. Claro que, dado ser a escola uma instituição inserida em uma estrutura social mais ampla, essas mudanças encontram obstácu- los diversos como, por exemplo, a adoção de princípios interdisciplinares e de transversalidade que sejam os mais visíveis. No caso da EA, por princípio concebida como teoria e prática interdisciplinar, resta o desafio, ainda não resolvido, de como ministrá-la e introduzi-la no cenário disciplinar das escolas (Carvalho, 2002b; Lima, 2005).

Em linhas gerais, esses são os pontos e argumentos principais apontados e propostos pela EA crítica com relação à EA conservacionista e que se colocam como as premissas básicas para a construção de outra concepção, que passa a se colocar como alternativa na disputa no interior de um campo comum.

Foi a partir dessa crítica à EA conservacionista que surgiu no debate a necessidade de alguns autores requalificarem esta por meio de novos adjetivos que a redefiniam como EA crítica, EA transformadora, EA popular, EA emancipatória, entre outros qualificativos. Todos esses esforços expressavam, de alguma forma, uma insatisfação com o tratamento reducionista dado à EA por leituras biologizantes, conservacionistas, tecnicistas ou comportamentalistas e com as implicações resultantes dessas abordagens.

É importante dizer que esse processo de mudança no campo da EA brasileira se desenvolveu, simultânea e articuladamente, a um conjunto de mudanças históricas e sociopolíticas que compreendeu a redemocratização do regime político a partir da década de 1980; a substituição do governo militar por um governo civil, embora ainda a partir de eleições indiretas; o surgimento de movimentos sociais e de ONGs com novas feições autonomistas e participativas; o amadurecimento da problemática ambiental no país; a ampliação do debate social e ambiental com a constituição de novos fóruns regionais, nacionais e internacionais; e a consequente aproximação entre setores dos movimentos sociais e dos movimentos ambientalistas, dando origem ao que ficou conhecido como socioambientalismo.

Vimos acima como o período inicial do ambientalismo no Brasil foi marcado por uma série de incompreensões e divergências entre os movimentos sociais e ambientais que dificulta- 
ram sua expansão e legitimação no país. Talvez, a Conferência do Rio em 1992 - Rio-92 tenha sido o momento mais ilustrativo dessa tessitura socioambiental, na medida em que estimulou o diálogo entre grupos representantes de ambos os movimentos, permitindo a descoberta de reivindicações e objetivos de luta convergentes que mereciam ser cultivados.

Durante esse período da Conferência do Rio, incluídas a fase preparatória e a imediatamente posterior ao evento, a EA viveu um momento de grande efervescência e de renovação quando se construíram novas identidades, se demarcaram novas definições conceituais e se firmaram posições e alianças políticas importantes para a reorganização do próprio campo. Foi nesse momento, por exemplo, que foram elaborados o Tratado de Educação Ambiental para a Responsabilidade Social e as Sociedades Sustentáveis e a Carta da Terra, documentos fundamentais para a orientação ética e política do campo; e se formou a Rede Nacional de Educação Ambiental - REBEA - que promoveria, após a Rio-92, a realização de dois Fóruns Nacionais de EA que se somaram aos outros dois já realizados antes da Conferência (Carvalho, 2001).

Finalizo esse item apontando que foi nesse período, de meados da década de 1980 até a Rio92, que se gestou e ganhou importância o discurso de DS, fruto do aprofundamento e cruzamento da crise do desenvolvimento econômico com a crise ambiental. Significa dizer, como já indiquei acima, que amadurecia a consciência de que os problemas do crescimento econômico e da degradação ambiental não eram diferentes nem concorrentes, mas simplesmente causa e efeito de uma mesma e inseparável equação.

\section{Educação ambiental: desenvolvimento sustentável ou sociedades sustentáveis?}

A partir de 1992, o discurso do DS se tornou a expressão hegemônica no debate que envolve as questões de meio ambiente e de desenvolvimento social em sentido amplo.
Compreendo o DS como uma estratégia político-diplomática da Comissão Mundial sobre Meio Ambiente e Desenvolvimento - CMMAD das Nações Unidas, mais conhecida como Comissão Brundtland, criada para examinar as questões críticas que envolviam a relação entre 0 meio ambiente e o desenvolvimento e oferecer propostas para orientar as relações internacionais, as políticas e as ações de mudanças necessárias nesse campo (CMMAD, 1991).

Em minha visão particular, a noção e o discurso do DS surgiram para substituir o discurso do desenvolvimento econômico difundido e experimentado nos países da periferia do capitalismo na esteira da Guerra Fria e, em franco processo de esgotamento, justamente porque não atendeu às expectativas e promessas de desenvolvimento, progresso e bem-estar social anunciadas. Na verdade, a experiência demonstrou, como é fartamente documentado, que as desigualdades sociais se aprofundaram como também a dependência financeira, tecnológica e cultural em relação aos países centrais; os regimes autoritários se ergueram; e uma crescente degradação ambiental decorria do modelo conservador de industrialização implantado nesses países (Santos, 2000; Sachs, 2002; Porto-Gonçalves, 2004; Goldenstein, 1994; Leroy, 2002).

Pode-se dizer que, a partir de uma perspectiva político-econômica, o sistema capitalista precisava encontrar meios de renovar-se técnica e ideologicamente para reconquistar os níveis de produtividade e lucratividade ameaçados com a crise econômica e do Estado de bem-estar social a partir de meados da década de 1970. Esses objetivos se concretizaram por meio do processo de reestruturação capitalista ${ }^{2}$ engendrado pelas teses e políticas neoliberais que então passaram a consolidar uma nova hegemonia internacional. A questão ambiental nesse processo aparecia como um desafio novo que ameaçava a reprodução sistêmica, tanto do ponto de vista da oferta de recursos naturais para a expansão econômica

2. Para maiores detalhes sobre o processo de reestruturação do capitalismo, ver, por exemplo, Antunes (1999) ou Wallerstein (1999). 
quanto da perspectiva dos resíduos da produção e da poluição daí decorrente.

Segundo Carvalho (apud Ribeiro, 1991):

Desde a Conferência de Estocolmo, em 1972, ficou claro que a preocupação dos organismos internacionais quanto ao meio ambiente era produzir uma estratégia de gestão desse ambiente, em escala mundial, que entendesse a sua preservação dentro de um projeto desenvolvimentista. Dentro dessa perspectiva produtivista, o que se queria preservar de fato era um modelo de acumulação de riquezas onde o patrimônio natural passava a ser um bem. 0 apelo à humanidade e ao bem-estar dos povos era usado como álibi, sempre citado ao lado dos objetivos de crescimento econômico, emprestando uma preocupação humanista a intenções não tão nobres. (p. 79)

Naturalmente que essa operação político-diplomática também buscava responder aos questionamentos sobre os limites do crescimento, intensamente discutidos na década de 1970; pacificar os conflitos na relação entre os países do eixo norte-sul, separados por assimetrias sociais, econômicas e políticas, que tensionavam historicamente as relações internacionais; e atender às demandas e críticas do movimento ambientalista internacional, que reivindicava a inclusão da questão ambiental na agenda de prioridades político-econômicas contemporâneas (Lima, 1997).

Como sabemos, o discurso do DS penetrou diversos campos de saber e de atividade, entre os quais o da educação. Desde a década de 1990, dissemina-se - entre organismos internacionais, organizações não governamentais e políticas públicas dirigidas à educação, ambiente e desenvolvimento de alguns países - a proposta de substituir a concepção de educação ambiental, até então dominante, por uma nova proposta denominada de Educação para o Desenvolvimento Sustentável - EDS 3 .

Essa estratégia capitaneada pela UNESCO, com apoio de governos, políticas públicas educa- cionais, universidades e ONGs, surgiu com maior força nos países da Europa ocidental e América do Norte, mas gradualmente se mundializou por meio dos canais normativos que regulam a política, a economia, os discursos educativos e ambientais nas relações internacionais.

Essa renovação discursiva e política tem estimulado um amplo debate que busca compreender os significados, os interesses e as implicações da nova proposta. Resulta igualmente numa disputa político-ideológica e pedagógica pela definição e orientação dos discursos, das práticas e das relações entre a sociedade, a educação e o meio ambiente.

Obviamente que essa proposta reedita e reproduz todo o debate sobre o discurso do DS com todas as ambiguidades e contradições que o caracterizam. Um questionamento inicial desste debate poderia ser: se não definimos com clareza e consenso o DS, como formular uma educação que, por princípio, está orientada a ele?

Ou seja, dada a diversidade de sentidos atribuíveis a essa noção e à própria incompatibilidade entre algumas de suas premissas, educar para o DS converte-se numa expressão vazia e duvidosa. Nada nos garante que chegaremos a bom termo ao "comprarmos esse pacote". Nesse sentido, é possível comparar a aceitação dessa proposta à situação de um passageiro que decide tomar um trem sem conhecer seu destino.

Entre os educadores ambientais brasileiros - e em alguns países latinos - a proposta da UNESCO gerou resistências porque a EA construída ao longo das últimas décadas no país tem revelado uma tendência a incorporar as questões sociais e a manifestar interpretações críticas da relação entre a sociedade, a educação e o meio ambiente, diferentemente do que acontece nos países europeus mais afeitos a versões conservacionistas e/ou preservacionistas de EA (Carvalho, 2002a; Lima, 2003; Sato, 2005).

3. Ilustra o fato a iniciativa da UNESCO de instituir, em 2005, "A década da educação para o desenvolvimento sustentável". 
Nesse sentido, substituir o termo EA por EDS representaria um retrocesso político, pedagógico e epistemológico, na medida em que estaríamos trocando uma história identitária afinada e comprometida com um socioambientalismo crítico-emancipatório por uma nova denominação que evoca tanto os traços economicistas dos velhos discursos desenvolvimentistas quanto as influências conservadoras do pensamento único da recente hegemonia neoliberal.

Carvalho (2002a), analisando essa proposta no contexto brasileiro, assinala que aqui o qualificador ambiental não é um mero adjetivo. Para ela, o ambiental constitui antes um traço identitário significativo da EA brasileira que a remete a seu contexto histórico de formação marcado pela redemocratização, pela emergência de novos movimentos sociais e seu ethos de resistência política, de crítica social e contracultural. Nesse sentido, ela percebe, nessa intenção de renomear a EA, uma disputa simbólica, ética e política entre uma tradição de crítica radical da sociedade capitalista industrial e de consumo e um outro ideário modernizador e desenvolvimentista de corte neoliberal, a partir do qual é formulada a noção de DS. Esse movimento estaria, assim, operando uma colonização e um esvaziamento dos ideais emancipatórios anteriores para substituí-los por outros valores e sentidos associados a um neoambientalismo de face mercadológica. Conclui, portanto, que essa mudança capitaneada pela UNESCO representa não um avanço, mas um retrocesso na medida em que:

[...] adotar uma educação para o desenvolvimento sustentável pode pôr em risco uma identidade, uma tradição e um capital simbólico que sustenta a utopia ambiental de uma luta contra-hegemônica e emancipatória para capitular diante desse instável conceito, que nasce do coração do status quo - tantas vezes denunciado pela crítica ecológica como a raiz dos problemas socioambientais. (p. 6)

Meira (2005), observando o discurso fundador da EDS, não vê razões pedagógicas, teórico-metodológicas ou epistemológicas que justifiquem a troca de uma EA por uma EDS. Ao contrário, diz que foram os jogos de poder e de interesse nos círculos das Nações Unidas - mais relacionados à agenda desenvolvimentista do que ao campo educativo-ambiental - os argumentos decisivos nessa genealogia. Concorda que "o que está em jogo é uma luta simbólica pela apropriação do conceito de sustentabilidade" (p. 6). Nesse confronto, opõe-se uma visão que utiliza o conceito de sustentabilidade como referência para formular e promover mudanças econômicas, políticas, ambientais e culturais para a crise ambiental e social, e uma outra visão que dele faz uso para justificar o crescimento econômico necessário à reprodução sistêmica.

Sauvé (1999), tratando o mesmo debate no contexto de crise da modernidade e de insurgências pós-modernas, observa na proposta da UNESCO um conjunto de problemas conceituais, éticos e culturais que reduzem a EA a uma ferramenta do DS. Para a autora, a EDS transparece uma ênfase desenvolvimentista, instrumental e conservacionista - valora o ambiente como recurso econômico para fins produtivos - que caracterizam justamente 0 projeto da modernidade em crise, tantas vezes responsabilizado pela crise socioambiental. Segundo a autora, não é aceitável eleger o DS, com toda sua polissemia e carga economicista, como valor supremo de qualquer sistema ético, sobretudo, se pensamos em orientar a partir dele as políticas e reformas educacionais que formarão os cidadãos.

Culturalmente, considera importante lembrar que os princípios da EDS foram definidos por indivíduos em sua maioria europeus, brancos, do sexo masculino, de classe média ou alta, profissionais de alta escolaridade e que estão, por conseguinte, impregnados de visões de mundo e de valores que não podem ser universalizados. Pondera que a própria concepção de tempo implícita na noção de desenvolvimento - entendido como projeto orientado para o futuro - não é comum a outras tradições que tem maior referência nas dimensões 
do passado e/ou do presente. Para essas tradições, a idéia de viver projetado para o futuro não faz tanto sentido como faz para o imaginário e a cultura ocidentais.

Com relação ao enfoque pedagógico proposto pelo discurso oficial da EDS - leia-se UNESCO, organismos e agentes associados -, transparece o predomínio de um paradigma tecnológico-racional que

[...] associa a EDS com a transferência de conhecimento científico e tecnológico e considera a educação como meio de empregar o potencial humano a serviço de crescimento econômico. (Sauvé, 1999, p. 15-16)

Percebe-se do exposto que o pensamento crítico associado à EA, ao menos nos contextos brasileiro e latino, tende a rejeitar a nova proposta de EDS com base nos mesmos argumentos porque rejeitara o discurso do DS. Esses argumentos se contrapõem, sobretudo, à ênfase economicista implícita nas formulações discursivas hegemônicas do DS; à ausência de viabilidade da proposta de DS no contexto do capitalismo contemporâneo, em especial em sua roupagem neoliberal; à ambiguidade e às contradições inerentes aos próprios objetivos definidos; e ao universalismo com que se endereça a contextos sociais, ambientais e culturais tão diversos.

Para alguns analistas, tamanho descompasso entre intenção e prática acaba por reduzir o DS a uma expressão do "conservadorismo dinâmico", na qual se promovem mudanças discursivas e/ou "cosméticas" apenas para garantir que nada de fato se transforme na vida real (Guimarães, 1998).

A pretensão universalista inerente à noção de DS é outro aspecto discutido nesse debate. A crítica se dirige, sobretudo, à inadequação de se propor uma mesma estratégia de desenvolvimento para contextos com tantas diferenças ecológicas, econômicas, históricas, políticas, tecnológicas e culturais. Advertindo para a complexidade e para os riscos envolvidos em tal empresa, diversos analistas propõem a noção alternativa de sociedades sustentáveis para lembrar a impossibilidade de se generalizar soluções a contextos tão diferenciados e a necessidade de levar em consideração as multidimensões que compreendem qualquer projeto de mudança e de desenvolvimento social.

Diegues (1992), discutindo a crise do desenvolvimento, a nova adjetivação e os conteúdos introduzidos pela renovação discursiva da sustentabilidade, sistematiza pontos representativos do pensamento crítico e defende o paradigma das sociedades sustentáveis. Segundo ele:

[...] ganha sentido a ideia de que não existe um único paradigma de sociedade de bemestar (a ocidental) a ser atingido por vias do "desenvolvimento" e do progresso linear. Há a necessidade de se pensar em vários tipos de sociedades sustentáveis ancoradas em modos particulares, históricos e culturais de relações com os vários ecossistemas existentes na biosfera e dos seres humanos entre si. Esse novo paradigma a ser desenvolvido se baseia antes de tudo, no reconhecimento da existência de uma grande diversidade ecológica, biológica e cultural entre os povos que nem a homogeneização sociocultural imposta pelo mercado capitalista mundial, nem os processos de implantação do "socialismo real" conseguiram destruir. (p. 23)

Leff (2007), em sentido semelhante, também reage à hegemonia economicista expressa nas idéias de desenvolvimento e na recente versão de DS que se conjugam como única possibilidade de organização social. Para ele:

0 grande desafio socioambiental hoje é, portanto, romper com a ideia de um pensamento único e unidimensional, orientado rumo a um "progresso sem limites", que vem reduzindo, sufocando e superexplorando a natureza. E para isso não basta se firmarem acordos e convenções, que depois de colo- 
cados em prática vão ser regidos por essa mesma racionalidade instrumental e econômica que hoje questionamos, mas sim ir legitimando outras formas de compreensão da vida e da complexidade do mundo e uma nova ética da práxis no mundo. (p. 9)

Percebe-se do exposto que o pensamento crítico associado à EA brasileira tende, em sua maioria, a rejeitar a proposta da UNESCO de uma EDS pelos motivos explicitados e a defender uma outra concepção político-pedagógica de maior complexidade baseada nos valores da diversidade cultural, da autonomia política e da democracia participativa. E para expressar esses valores e resistência, vale-se da expressão sociedades sustentáveis como caminho alternativo.

\section{Considerações finais}

Procurou-se, neste artigo, refletir sobre a trajetória histórico-social, política e pedagógica do que se convencionou nomear no Brasil em décadas recentes de EA crítica. Qual o contexto sociopolítico de seu surgimento? Qual sua importância na disputa interna do campo da EA brasileira? Quais suas contribuições pedagógicas, ambientais e políticas? Quais suas principais influências e de quais argumentos se valeram para propor um caminho político-pedagógico diferente da EA conservacionista que marcou a formação inicial do campo? Essas são algumas das questões norteadoras com as quais dialogamos ao longo do texto.

Compreendemos, consoante o título escolhido, que a EA crítica se construiu como uma alternativa política e pedagógica afinada com o socioambientalismo e com o paradigma das sociedades sustentáveis nos termos colocados pelo, hoje já histórico, Tratado de Educa- ção Ambiental para Sociedades Sustentáveis e Responsabilidade Global. Como muitos sabem, o tratado foi fruto da construção coletiva da sociedade civil representada por ONGs e movimentos sociais de centenas de países na Conferência do Rio em 1992 e tem servido como referência simbólica e política de uma EA crítica, participativa e autonomista.

Não dispomos até o momento no país de pesquisas abrangentes capazes de mapear o estado da arte da EA praticada e das tendências político-pedagógicas dominantes na vasta extensão de nosso território. Sabemos, contudo, por uma visão impressionista apoiada na observação direta ${ }^{4}$, que essa concepção crítica de EA cresceu e deu frutos, e é possível arriscar dizer que é a expressão dominante, ao menos no que chamei de núcleo orientador do campo. Ou seja, ela convive e disputa em posição privilegiada no interior desse campo com outros tantos discursos e práticas de EA. De toda forma, o fundamental talvez seja constatar a contribuição decisiva que ela trouxe ao debate e à atividade educacional, associada ao meio ambiente e ao desenvolvimento, ao introduzir as reflexões indispensáveis da ecologia política, da complexidade e da ética socioambiental.

Seria insensato e contraditório pretender uniformizar o pensamento e a ação críticos, sobretudo, quando falamos de educação e de crítica, por “certa definição", livres e plurais. 0 pensamento crítico é sempre renovador e inquieto. Aciona o questionamento, o diálogo e a abertura ao novo. É pedra que rola, movimento e vida. Creio que o caso da EA crítica não é diferente: ela procura em sua expressão mais generosa a vida renovada, a integração inclusiva e a emancipação de todas as prisões.

4. Refiro-me aos títulos e artigos publicados e nos fóruns sociais, políticos e científicos sobre o tema. 


\section{Referências bibliográficas}

ANTUNES, R. Adeus ao trabalho: ensaio sobre as metamorfoses e a centralidade do mundo do trabalho. São Paulo: Cortez, 1995.

BECK, U. A reinvenção da política: rumo a uma teoria da modernização reflexiva. In: BECK, U.; GIDDENS, A.; LASH, S. Modernização reflexiva: política, tradição e estética na ordem social moderna. São Paulo: UNESP, 1997. p. 11-71.

CARVALHO, I. C. de M. Movimentos sociais e políticas de meio ambiente. A educação ambiental aonde fica? In: FÓRUM DE EDUCAÇÃo AMBIENTAL, 3, 1995, São Paulo. Cadernos... São Paulo: Gaia, 1995. p. 58-62.

A invenção ecológica: narrativas e trajetórias da educação ambiental no Brasil. Porto Alegre: Ed. UFRGS, 2001.

. 0 "ambiental" como valor substantivo: uma reflexão sobre a identidade da educação ambiental. In: SAUVÉ, L.; ORELANA,

I.; SATO, M. (Orgs.). Textos escolhidos em Educação Ambiental de uma América à outra. Tomo I. Montreal: ERE UQAM, 2002a. p. 85-90. (versão em português)

Qual educação ambiental?: elementos para um debate sobre educação ambiental popular e extensão rural. In: SIMPÓSIO SUL BRASILEIRO DE EDUCAÇÃO AMBIENTAL, 1, 2002, Erechim. Anais... Erechim: EdiFAPES, 2002b.

COMISSÃO MUNDIAL SOBRE MEIO AMBIENTE E DESENVOLVIMENTO - ONU. Nosso futuro comum. 2. ed. Rio de Janeiro: Ed. FGV, 1991.

DIEGUES, A. C. Desenvolvimento sustentável ou sociedades sustentáveis: da crítica dos modelos aos novos paradigmas. São Paulo em Perspectiva. v. 6, n. 1-2, p. 22-29, jan./jun., São Paulo, 1992.

FERREIRA, L. da C. Conflitos sociais contemporâneos: considerações sobre 0 ambientalismo brasileiro. Ambiente \& Sociedade, Campinas, n. 5, 2 sem., 35-54, 1999.

GADOTTI, M.; TORRES, C. A. (Orgs.). Educação popular: utopia latino-americana. São Paulo: Cortez, 1994.

GOLDENSTEIN, L. Dependência e desenvolvimento. In: Repensando a dependência. Rio de Janeiro: Paz e Terra, 1994.

GUIMARÃES, R. P. 0 desafio político do desenvolvimento sustentado. Lua Nova, São Paulo, n. 35, p.113-136, 1995.

Modernidad, medio ambiente y ética: um nuevo paradigma de desarrollo. Ambiente \& Sociedade, Campinas, ano I, n. 2, p. 5-24, $1^{\circ}$ sem. 1998.

LEFF, E. Educação ambiental e desenvolvimento sustentável. In: REIGOTA, M. (Org.). Verde cotidiano: 0 meio ambiente em discussão. Rio de Janeiro: DP\&A,1999.

. Precisamos de uma nova racionalidade. SENAC e Educação Ambiental, ano 16, n. 1, jan./abr. 2007.

LEROY, J. P. et al. Tudo ao mesmo tempo agora: desenvolvimento, sustentabilidade, democracia: 0 que isso tem a ver com você? Petrópolis: Vozes, 2002.

LIMA, G. F. da C. 0 debate da sustentabilidade na sociedade insustentável. Política \& Trabalho, n. 13, p. 201-222, João Pessoa: PPGS/UFPB, set. 1997.

. 0 discurso da sustentabilidade e suas implicações para a educação. Ambiente \& Sociedade, NEPAM/UNICAMP, Campinas, v. 6, n. 2, jul.-dez., 2003.

. Formação e dinâmica do campo da educação ambiental no Brasil: emergência, identidades, desafios. 2005. 207 p. Tese (Doutorado)- Instituto de Filosofia e Ciências Humanas, Universidade Estadual de Campinas, Campinas, 2005.

LIPIETZ, A. A ecologia política: solução para a crise da instância política? In: ALIMONDA, H. (Ed.). Ecologia política. Buenos Aires: CLACSO, 2002.

LOUREIRO, C. F. B. Trajetória e fundamentos da educação ambiental. São Paulo: Cortez, 2004. 
Educação ambiental e teorias críticas. In: GUIMARÃES, M. (Org.). Caminhos da educação ambiental: da forma à ação. Campinas: Papirus, 2006.

MEIRA, P. Elogio da educação ambiental: da década da educação ambiental para o desenvolvimento sustentável ao milênio da educação ambiental. In: Jornadas Pedagógicas da Educação Ambiental: Educação ambiental no contexto da década das Nações Unidas da educação para o desenvolvimento sustentável (2005-2014). 12., Ericeira, Anais..., 2005 p. 14-18. (Conferência).

MORIN, E. (Org.). 0 problema epistemológico da complexidade. Portugal: Europa-América, 1996.

ORLANDI, E. P. 0 discurso da educação ambiental. In: TRAJBER, R.; MANZOCHI, L. H. (Coords.). Avaliando a educação ambiental no Brasil: materiais impressos. São Paulo: Gaia, 1996. p. 37-58.

PORTO-GONÇALVES, C. W. 0 desafio ambiental. Rio de Janeiro: Record, 2004.

RIBEIRO, G. L. Ambientalismo e desenvolvimento sustentado: nova ideologia/utopia do desenvolvimento. Revista de Antropologia, São Paulo, n. 34, p. 59-101, 1991.

SACHS, I. Caminhos para o desenvolvimento sustentável. Rio de Janeiro: Garamond, 2002.

SANTOS, T. dos. A teoria da dependência: balanços e perspectivas. Rio de Janeiro: Civilização Brasileira, 2000.

SATO, M. Identidades da educação ambiental como rebeldia contra a hegemonia do desenvolvimento sustentável. In: Jornadas da Associação Portuguesa de Educação Ambiental: Educação Ambiental nas Políticas do Desenvolvimento Sustentável. Lisboa, Anais..., ASPEA, 2005. (Conferência).

SAUVÉ, L. La educacion ambiental entre la modernidad y la posmodernidad: em busca de um marco de referencia educativo integrador. Tópicos, v. 1, n. 2, aout, 1999. p. 7-27.

STRECK, D. R. A educação popular entre a tradição, a modernidade e a pós-modernidade. Educação \& Sociedade, ano XVII, n. 57, Especial, CEDES, Campinas, dez. 1996.

VIOLA, E. 0 movimento ambientalista no Brasil (1971-1991): da denúncia e conscientização pública para a institucionalização e 0 desenvolvimento sustentável. In: GOLDENBERG, M. (Org.). Ecologia, ciência e política. Rio de Janeiro: Revan, 1992.

WALLERSTEIN, I. A reestruturação capitalista e o sistema-mundo. Petrópolis: Vozes, 1999.

Recebido em 19.02.08

Aprovado em 08.12 .08

Gustavo Ferreira da Costa Lima, mestre em sociologia pela UnB e doutor em sociologia ambiental pelo Instituto de Filosofia e Ciências Humanas - UNICAMP, tem atuado como professor e pesquisador nas áreas temáticas que envolvem sociologia ambiental, educação ambiental, desenvolvimento sustentável e movimentos sociais. 